\title{
Aurobindo's Thought and Holistic Global Education
}

\author{
Stephen R. White \\ Appalachian State University
}

The integral knowledge admits the valid truth of all views of existence, valid in their own field, but seeks to get rid of their limitations and negations and to harmonize and reconcile these partial truths in a larger truth .... It is not by "thinking out" the entire reality, but by a change of consciousness that one can pass from the ignorance to the Knowledge-the Knowledge by which we can become what we know. (Dalal, 2001, p. 3)

—Sri Ghose Aurobindo (1872-1950)

\section{The Age of Globalization}

Contemporary global, political, social, and economic developments may forever transform the way we think about each other and influence the future social reality constructed. Latest acts of terrorism will certainly have an influential effect on humankind's collective psyche. The materialization of these emerging global issues are especially challenging for educators. As such, many assert that humankind now has a collective responsibility to facilitate the construction of a shared global culture through educational socialization. This is particularly true for those of us who are professionally committed to educating toward a future existence where peaceful cooperation and planetary citizenship become dominate values that are held in the same high regard as nationalism and individualism are today. Within this context it is critical that we reflectively contemplate what we teach and how we teach regarding these issues.

Some scholars view these developments of international change as the 
emergence of a new social phenomenon. This social phenomenon coming to life is termed globalization. Globalization is the idea that humankind is evolving into an interconnected political socioeconomic system. The majority of scholars study globalization from the perspectives of transnational political conflicts in the quest for a world governance, the effect of global social interconnections on economic justice, and the impact of scientific and technological innovations on global relations (Baylis \& Smith, 2001; Beck, 1999; Berger \& Huntington, 2002; Bhagwati, 2004; Bloom, 2000; Bruteau, 2001; Foer, 2004; Friedman, 2000, 2005; Held \& McGraw, 2000; Held, McGraw \& Perraton, 1999; Hubbard, 1998; Steger, 2001; Stiglitz, 2002).

Nevertheless for many educators globalization has become a significant concern at all levels of learning, which is why they many seek to move the focus beyond being purely an international political and socioeconomic problem, to one that is viewed philosophically as a global humanitarian dilemma as well. In view of this increased interest in global education, we examine the ideas of Sri Ghose Aurobindo and Scott Forbes to determine the value of their thoughts on this subject. Before we examine their views, however, a succinct review of some relevant literature by global education theorists is undertaken. Special attention is given to how certain educators understand the problem of globalization, conceive of means to educate for it, and articulate global educational agendas.

\section{Globalization and Global Education: A Literature Review}

While other global education experts could have been selected, Patrick Fitzsimmons, Dean Peterson, Delores Wunder, Harlan Mueller, Jean-Bertrand Aristide, Val Rust, Bill Bigelow, Bob Peterson, Nicholas Burbles, Carlos Torres, Holger Daun, Nelly Stormquist, Karen Monkamn, and John Levin have been included to illustrate the diversity of thought in global education and the conceptual and philosophical challenges that exist. As we begin with Patrick Fitzsimmons, it is of interest that he contends that the political ideology of neo-liberalism is the social force behind the globalization movement, which he views as problematic because the neo-liberal agenda is a homogenizing process. Neo-liberalism advocates an international "politics of difference" under the guise of "global cooperation," which is a pretext that undermines genuine social solidarity and cohesion. He believes neo-liberalism is a conscious political deception advanced by a few international power brokers in order to advance their specific interests, and it is not an idea to motivate global unification or legitimate cooperation. Fitzsimmons proposes an educational agenda that promotes "critical localism" and 
"critical regionalism." The goal of these two notions is to counterbalance the false perception of global unity and cohesion that current neo-liberalism fallaciously champions (Rizvi \& Lingard, 2002).

The theory of "subjective globalization" is the focus of D. Peterson, Wunder, and Mueller's work. Subjective globalization is the idea that globalization requires a re-conceptualization from two perspectives: (1) personal identities and (2) nationalistic boundaries. Educational socialization into our era of globalization requires a transformation of learners' personal identities regarding "what" they represent and "who" they are within the context of cooperative global relationships. They believe that political nation-state boundaries are an artificial social reality of global segregation. This world-view undermines an individual's global identity and hinders collective social action. Thus an effective global education program must be designed specifically to assist learners to intellectually reframe their identity of self as existing within the larger integrated global community (Peterson, Wunder, \& Mueller, 1999, pp. 19-20).

How can we infuse various issues regarding globalization throughout the curriculum is the concern of Aristide. Her contention is that the incorporation of globalization into the curriculum must be from the perspectives of "those from below"-marginalized Third World peoples. That is, global education must seek to help learners understand and improve the socioeconomic conditions of exploited peoples. Globalization demands that educators teach critically and explore various solutions from the views of those who suffer under the conditions brought about by recent global socioeconomic and political expansion (Bigelow \& Peterson, 2002).

Globalization has had a deep impact on Third World educational policy. Burbles and Torres have researched how globalization has had an impact on educational policies and practices. They state: "[Our research] is primarily a work of theory, these discussions contain specific and concrete implications for how education is changing, and how we will need to change, in response to new [global] circumstances" (Burbles \& Torres, 2000, p. 2). Their research has sought to identify political, social, and economic factors of globalization that are having a direct impact on the philosophy and policies of education in Third World regions and suggest alternative educational processes.

Likewise, Daun (2002) has also centered his work on the impact of global politics and economic interest on education. He thinks that First World national economic expansion is the real meaning of globalization. The result of this national interest is that education is serving as the forum for international political ideological wars. The idea of globalization simply provides the political context to argue for greater governmental bureaucratic oversight in order to increase the quantity 
and quality of public education, globally. Economically powerful nations advance the idea of global cooperation and equality as a political veil in order to multiply capital gains through the exploitation of peoples in less influential nations. The economic interests of First World nations and groups are in constant need of skilled workers to increase their materialistic gains and the human resources supply is satisfied by increasing the educational level of marginalized peoples. Daun calls for the education of Third World peoples so that they become conscious of the First World interests and their potential for exploitation. When the social consciousness of marginalized peoples is elevated, they will become empowered to govern externally funded educational agendas so that their socioeconomic needs are met through their own formulated indigenous educational policies and programs.

Some global educators center their research on ways in which to develop a stronger knowledge base and on teaching and learning processes regarding globalization. Such is the case for Bigelow and B. Peterson who take a curricular and pedagogical position regarding globalization as an educational problem. For them the challenge of globalization for educators is to design innovative curriculum around life-world issues and to teach for global social justice. They write: "It is impossible to separate our teaching about wretched conditions of workers around the world from all the factors that produced the desperation that forces people to seek work in those conditions" (Bigelow \& Peterson, 2002, p. 3).

Several educational theorists perceive globalization as a socioeconomic problem that is inherently a political issue of international conflict for power controls. Rust represents this camp of thinkers, in that he asserts that international economic motives extend the problem of globalization far beyond socioeconomic relationships. The issue of globalization is also a problem of nationalistic power conflicts. He advocates an activist educational agenda that advances the capitulation of our mental model of political sovereignty that essentially segregates nationstates into flash points of conflict. Rust believes that the emergence of transnational corporations, multinational socioeconomic consortiums, and the formation of global organizations (such as environmental associations) along with the conflicts that emerge between these groups are the problems to be addressed through global education programs (Stromquist \& Monkman, 2000).

Geopolitics is also having an impact on educational thought. Within this context Stromquest and Monkman have explored the question of what kind of education will prevail in a globalized world:

Will it only be to make us more productive and increase our ability to produce and consume or will it be able to instill in all of us a democratic 
spirit with values of solidarity? This solidarity will have to recognize the different interests among men and women and amongst the dominant groups and disadvantaged groups. (Stormqueist \& Monkman, 2000, pp. 21-22)

What's more, Stromquist contends that educational theorizing about globalization is an intensely convoluted undertaking because it is a multifaceted sociological phenomenon and an intensely interdisciplinary educational dilemma. This is the case because the perception of globalization varies depending on the position that is being advanced when defining it. Globalization can be framed from conservative, neo-liberal, critical theory or postmodern perspectives while defining diverse problems such as global convergence and cultural divergence, worldwide social homogenization or global hetrogenization, and local needs that are in conflict with national, regional, and international interests (Stromquist, 2002, pp. 1-13).

Community college educator Levin states that globalization reflects a perception that the world is becoming a shared social space due to technological and economic forces. The globe has become so interconnected that there is now a common agreement that it is having a profound impact on education's conceptual framework in both Canada and the United States. He states:

It may be that consciousness of a global society, culture, and economy and global interdependence are the cornerstones of globalization, and these - consciousness and interdependency—have saliency in knowledge based enterprises.... there is certain inevitability that higher education institutions, because of their cultural, social and economic roles, are caught up in and affected by globalization. (Levin, 2001, p. 9)

This succinct survey of these global educators reveals the diversity of thought regarding the conceptual and philosophical challenges that exist due to globalization. Obviously there does not exist "one best way" to meet the educational challenge, yet there is a consent that a genuine need does exist in global education requiring creative collective thinking about the future of humankind.

Perhaps due to the immediate impact of global political, social, and economic issues, idealistic thought holds minimal interest for most global educational thinkers and their agendas. Most global educators have a realist critical theory orientation toward globalization as solely being a conflict of power issues. Philosophical idealists, who visualize recent global developments as an opportunity to explore the possibility of greater social evolution beyond our present state of turmoil, have a small voice in educational dialogue. Nevertheless, we should not abandon the task of exploring new ideas and advancing novel visions of globalization that 
can also be integrated into educational praxis. Holistic educational thought is one place for contextualizing rational idealistic thinking about globalization.

\section{Forbes and Holistic Education Theory}

The field of holistic education has as its primary goal the fullest possible development of learners' self-actualization. Such development of the learner includes higher levels of consciousness through educational intellectual development while also cultivating their relationship with others in society. The advancement of society is held to be a consequential correlation to facilitating a person's self-actualization. Thus, the concern of holistic educational theorists is to expand the learning processes beyond conventional modes of knowledge dissemination and competencies in order to include deeper levels of the individual's consciousness with the greater evolution of society as a consequence of the process.

Forbes is a theorist of holistic education, who has addressed the issue of placing social idealism in the curriculum along side the critical realism of life-world problems. He argues that social transformation will not occur without a sense of vital purpose, an idealistic vision for the future. $\mathrm{He}$ believes that an effective motive for social action will not emerge if there does not also exist the "Ultimate Ideas of Purpose." To educate towards the construction of a future social order that is a greater state of existence than our present social order without an idea of ultimate meaning is like putting the cart before the horse. Ideas of ultimacy construct for learners a meaningful mental model of selfhood that can result in collective social action. Holistic education is the proper theoretical forum from which to promote idealism of ultimate meaning (Forbes, 2003, pp. 18-22).

Forbes thinks that education can advance a shared idealistic vision of the future subjectively relevant to the individual and motivationally significant for the collective. He believes that the advancement of a positive vision of the future of humankind and the advancement of social progress is one of the noblest roles an educator can seek. However, effective social action requires as its foundation a positive idealistic concept of ultimacy. Thus, without a notion of ultimacy, it is impossible to educate learners toward constructing a meaningful understanding of globalization that has the inspirational power to transform consciousness and society (Forbes, 2003, pp. 22).

Given Forbes proposition, global educators can deduce that unless we construct ideas of Ultimacy it is not probable to educate learners toward constructing a meaningful perceptive of globalization that also has the motivational vigor to persuade them to become political and 
social change agents. His hypothesis supports the suggestion in this work that the thought of Aurobindo is a worthy source from which to educationally construct an idea of Ultimacy regarding globalization.

\section{Life of Aurobindo}

Philosopher Aurobindo (1872-1950) can be viewed as a $20^{\text {th }}$ Century Renaissance person. Hewas an avant-garde intellectual who intensely analyzed human and social evolution. In doing so, he sought to philosophically reconcile Western science with Eastern metaphysics into an integrative narrative of reality. Born in Calcutta, India, Aurobindo was educated at Cambridge University. His academic interests were interdisciplinary in scope: liberal arts, political science, sociology, psychology, philosophy and education. He was profoundly influenced by western thought; especially the realms of empirical positivism, rationalism, and romantic idealism. Charles Darwin's evolutionary theory, Henri Bergson's philosophy of cognitive evolution, and G. F.W. Hegel's idea of dialectical social evolution made a significant impression on his intellectual development and world-view. The idea of human evolution as perpetual motion became the cornerstone of his thought (Chaturvedi, 2002; Dalal, 2001; McGreal, 1995; Purani, 2001; Sethna, 1981; Susai, 1993).

After graduation from Cambridge, Aurobindo returned to India and became an extraordinary political statesmen and a passionate revolutionary in the people's struggle for national liberation from British governmental control. Due to the depth of his political activism, the British authorities labeled him the most dangerous revolutionary in India's battle for independence. Eventually he was captured and charged for sedition and imprisoned to solitary confinement. While in prison he went through a spiritual transformation. He claimed to have experienced a Divine presence "as all beings and all that is" and visualized reality as unified. As a result of this experience, he became deeply absorbed in the study of Hinduism. The Eastern notion of metaphysical monism, a non-dualistic Absolutely Reality that exists behind the empirical world of physical appearance, became infused throughout his thought along with that of perpetual evolution. Affection for him by the Indian people became legendary. In time, his fellow countrymen affectionately refer to him with the honorific designation of "Sri" Aurobindo (The term "Sri" is from the Sanskrit language, a Hindu honorific title meaning-"Master") (Bruteua, 1974; Feys, 1977; Heehs, 1989).

Around the time of the mid 1940s, Aurobindo became convinced that his political activism for India's nation-states was now complete. From this point forward he became committed to political action and 
social service as being the process of advancing a conscious transformation of all humankind. He viewed himself as a spiritual revolutionary advocating a new politics of consciousness. He argued that because of humankind's unique evolution as a species, we were now the collective custodians of future evolution. From this realization, Aurobindo began writing volumes of scholarly works on social issues and while philosophically developing a metaphysical idealism of "Ultimacy" (Gandhi, 1992; Heehs, 1999; Singh, 1989; Varma, 1998).

Aurobindo believed that Hindu spirituality and meditative yoga would augment his new vision of political thought, social work, and the quest for self-realization as interconnected activities. Thus he developed a system of yoga-Integral Yoga. Integral Yoga seeks to change our inner-self (psyche) and outer-life (social disposition) as a manifestation of a higher level of consciousness. Overall, his system of yoga was a synthesis of Western psychology, which focuses on the outer personality and social behavior, with Eastern spirituality which focuses on the inner person and the psyche. In other words, Integral yoga is not a specific physical or psychological procedure, but it is to consciously surrender to the numinous energy that pushes the evolutionary process (Aurobindo, 1971, 1985a, 1990, 1993, 1998a; Dalal, 2003; Kluback, 2003; Overzee, 1992; Rishabachand, 1993; Susai, 1993; Vrekehm, 1998; Wygant, 2001).

Aurobindo states:

The way of yoga must be a living thing not a mental [psychological] principal or a set [physical] method to be struck to against all necessary variations... a spiritual evolution, an evolution of consciousness in matter is a contrast developing self-formation till the form can reveal the indwelling spirit...the central significant motive of the terrestrial existence. (Chaturvedi, 2002, pp. 54-55)

After the emancipation of India, Aurobindo devoted himself entirely, along with his wife, the French mystic Mirra Alfassa-referred to as The Mother, a Hindu honorific title-who would liberate the whole of humanity socially and spiritually by advancing psyche evolution and conscious transformation while pressing forward the construction of a new social reality of global unity (Bruteau, 1971; Vrekehm, 1998).

Indian scholar Atulindra Nath Chaturvedi portrays Aurobindo as one of the pillars of India's reawakening. He states:

However, none [Tagore, Nehru, Ghandi] bridged the divide between the political and spiritual as did the political activist Aurobindo Ghose, who blazed across the political firmament like a shooting star then, as the sage Sri Aurobindo, became the beacon whose light still draws millions. How the political pathfinder in a nation striving for libera- 
tion transformed himself into a rational mystic with a universal vision remains a continuing puzzle. (Chaturvedi, 2002, p. 5)

We will now explore more deeply the thought and philosophical concepts of this most fascinating intellectual.

\section{Aurobindoian Thought: Human Evolution toward Global Unity}

Although he wrote volumes on various subjects, of interest to this study, there are two particular works that define Aurobindo's thought regarding human and social evolution. The life divine (1974a) can be viewed as his philosophical magnum opus while The future evolution of man (1974b) is his most ambitious sociological analysis. Both of these works are examples of his theoretical synthesis of Western evolutionary thought and Neo-Hinduism as a narrative of his thought regarding the relationship between psyche involution and social evolution (Heehs, 1999; Susai, 1993; Zaehner, 1971).

Aurobindo's vision of the future is connected to our understanding of previous evolutionary stages, present state of existence and the Eastern notion of monism, Absolute Reality. He describes evolution as an eternal process with a universal energy causing a dialectical intercourse because of our spiritual descent into the world, resulting in an evolutionary assent of the human psyche. The Aurobindoian idea being that involution is the incarnation of the divine on earth through decent into the human psyche. Within this context, Aurobindo asserts that planetary evolution has resulted in the creation of four distinct yet unified earthly realms with a corresponding reality: Material realm (physical reality), life realm (biological reality), intellectual realm (psyche-social reality), and metaphysical realm (higher consciousness-spiritual reality). Each earthly realm has a discernable evolutionary direction of the psyche's development and elevated appearance of the consciousness (Aurobindo, 1974a, 1974b, 1998b; Bruteau, 1974; Combs, 1996; Vrekhem, 1998)

He describes how matter evolved into life resulting ultimately in the emergence of the human species with an elevated level of consciousness. With the advent of the human species, a more complex process of evolution was set in motion. Because evolution is in perpetual motion, it follows that the human specie cannot be the end point of evolutionary movement but is a unique transitional state of being (Aurobindo, 1974a, 1974b, 1985a, 1985b, 1998a, 1998b; Combs, 1996; Dalal, 2001, 2003; McGreal, 1995; Vrekehm, 1998).

Aurobindo's theory of evolution states that within the four earthly realms seven evolutionary states of psyche (mind), with distinctive degrees of consciousness more elevated than the previous level, have 
appeared: Physical mind is the most basic state of the brain producing elemental consciousness. Vital mind is the state of mind with a level of consciousness associated with meta-cognition and affective modes of thinking. Higher mind is an important transitional stage of evolution. It is a transitional state between base biological mind and that of reflective knowing (higher consciousness). Illuminated mind is a more complex level of consciousness that has characteristics of intuitive knowing and producing visionary thinking. Intuitive mind is a distinct state of mind and consciousness empowered by a perceptive awareness of Absolute Reality. This degree of consciousness is found manifested in extraordinary persons endowed with innovative insights and a novel sense of relevance regarding the future human evolution. Over mind is the next transitional state of mind. It is characterized by a transcendental level of consciousness and the cognitive ability for integrative thinking, holistic knowing and mystical insight. Accordingly, in our age a few individuals have emerged revealing this level of evolution. Those who have reached this evolutionary state are the pathfinders for future human evolution and advancing global-unity.

Supramind (that is Supermind) is the future highest level of psyche. It is a total transformation of the human species into a new breed of life and mind. While all the previous levels of minds are supported solely by physical and psyche realms of realities. Supramind is grounded upon Absolute Reality, the Life Divine. Supramind is the Life Divine fully manifested on Earth. He describes the Supramind as the human psyche bathed in divine energy that totally transforms consciousness and empowers individuals to reconstruct human relations into a new social reality of collective global unity (Refer to the Appendix: Diagram 1: Aurobindoian Global Idea of Psyche-Social Evolution) (Aurobindo, 1974a, 1974b, 1985b, 1991, 1998a, 1998c; Bruteau, 1971, 1974; Combs, 1996; Mukherjee, 1990; Satprem, 1984, 1985; Vrekehm, 1998).

Aurobindo writes:

The animal is the living laboratory of the evolutionary urge, illuminating and change must take up and re-create the whole being, mind, life, and body: it must not be only an inner experience of the divinity but a remodeling of both the inner and outer existence by its power; it must take form not only in the life of the individual but as a collective life of Gnostic beings [Supermen]. (Aurobindo, 1974a, p.68)

Aurobindo asserts that the notion of Life Divine is not a theory of an other worldly reality, strictly an esoteric mysticism. Life Divine is a tangible energy infusing ever-higher expressions of consciousness bringing about greater global social evolution. Supramind results in individuals becoming fully aware of their uniqueness as well as their 
psyche and social unification with others without perceived contradictions between the two. The complete involution of Life Divine on planet Earth will result in the birth of a new species, "Gnostic being," a being of knowledge, endowed with the capacity to steer future social evolution toward a state of global-unity (Aurobindo, 1998c; Mukherjee, 1990; Satprem, 1984, 1985; Vrekehm, 1998).

The involution of divine spirit into individual's psyche development is driving societies toward increasingly advanced levels of collective consciousness. As a result, societies will continue to evolve toward greater convergence constructing even higher degrees of collective consciousnesses and global social order.

He writes:

The appearance of mind and body on earth makes a critical step, a decisive change in the course of evolution. There is an evolution of the consciousness behind the evolution of the species and this spiritual evolution must end in a realization, individual and collective, on the Earth. Man is a transitional being who has seen that there can be a higher status of consciousness than his own. ...the being has become awake and aware of himself; there has been manifest in mind its will to develop, to grow in knowledge, to deepen the inner and widen the outer existence to increase the capacities of nature. Man has seen that there can be higher states of existence than his own. For truth and knowledge is an idle gleam if knowledge brings not power to change the world. (Aurobindo, 1974b, p.51)

Aurobindo asserts that the convergence of humanity into a cooperative global-unity will not result in an impersonal society of estranged individuals. Conversely, the transformation of consciousness will result in persons becoming free of self-interested ego driven individualism through becoming reflectively aware of their own psyche development within the context of others experiencing the same process. He theorized that humankind has entered a new age of accelerated personal involution resulting in collaborative social evolution on a global scale. The immediate future of humankind can be understood as the collective transformation of humankind occurring on individual and social levels.

He steadfastly believed that human progress and global convergence is occurring despite persistent international socioeconomic strife and political conflict. These current international ills are evolutionary pangs of a new age being born where global social collaboration and planetary consciousness are its defining characteristics. The "Ultimate" future of human evolution is not merely an individual affair but a collective global one. The collective exists by the individual, not vice versa, and a perfected global community can exist only if the members are perfected. 
The community exists to serve individuals, but it is the duty of the individual to sacrifice themselves for the sake of collective global unity. Accordingly he visualizes a future state of existence that will embrace us into a new collective social reality of authentic global-unity (Aurobindo, 1974, 1991; 1998a; 1998b; Bruteau, 1971).

We will now assess the relevance of Aurobindo's thought for global educators and how it is congruent with the goals of holistic educational thought. The hypothesis presented here is that a holistic global education learning agenda can be framed from the idealism of Auorbindoian thought, as well as provide the philosophical and social foundations from which to construct an idea of "Ultimacy" regarding globalization.

\section{Aurobindo's Thought and a Holistic Global Education Agenda}

Holistic educational thought thrives on advancing optimistic perspectives of humankind and society. The philosophical advocacy of exploring competing theoretical points of Ultimacy challenges educators to contemplate and honor diverse perspectives. The position in this work is that the utilization of Aurobindoian thought is within the philosophical disposition of holistic education and augments a novel global education agenda. We can conceive of this integrative synthesis between Aurobindoian thought and educating for our age of globalization as a model of a holistic global education agenda (Forbes, 2003).

Aurobindo's thought is an alternative perspective to the critical realist's critique of globalization. His theory is neither culturally eastern nor western in scope, but universally humanistic and globalist. His thought is not an analysis of globalization but is a global evolutionary mythos to be dialectically contrasted against diverse perspectives of globalization as demonstrated in the literature review of various global educators thought. The overriding educational agenda here is to provide learners with a futuristic and visionary idea of Ultimacy regarding globalization. Aurobindoian thought has core values that can serve as the foundational framework for a holistic global education agenda. A brief description of these core values follow:

$\mathrm{u}$ Perhaps the most significant educational value of Aurobindoian thought is the idea that humankind must become educated regarding the actual possibility of current globalization as a positive evolutionary movement. Aurobindo argued that contemporary political ideologies are insufficient to create a real sense of Ultimacy. Nationalism is an archaic idea exhausted of relevance to promote human solidarity and global-unity. Thus, what is required is a new sense of personal selfactualization and social identity within a global context. 
$\mathrm{u}$ If humankind is to survive current international conflicts, then a radical transformation of human consciousness must first occur to reconstruct society as a new cooperative global social order.

u Humankind as a species is still in evolutionary movement, and our current state of existence is only a transitory one. Current evolutionary movement is part of the progression of humankind towards a point of global unity.

$\mathrm{u}$ Consciousness is the apex of past evolutionary phenomenon and the expansion of consciousness, on both the individual and collective level, is the Ultimate goal of future human evolution.

u Conscious transformation has now empowered humankind to steer future evolutionary movement. For the next social evolutionary apex to be fully realized demands collaborative action and global solidarity on the part of humankind.

$\mathrm{u}$ What must precede this positive state of globalism with the transformation of the individual's consciousness so that it is also committed to reconstructing society into a new global reality. The far distant future is visualized as holding positive possibilities that will ultimately refurbish humankind into a new species of intellectual essence and social behavior.

These core values imbedded in Aurobindoian thought contextualize current globalization within a futurist intellectual framework of ultimate concern. This assertion is congruent with holistic education and Scott Forbes hypothesis that advancing an idealism of Ultimacy can potentially result in desired individual self-actualization and social transformation (Aurobindo, 1985a, 1991, 1998b; Dowsett, 1977; Dowsett \& Jayawal, 1976; Forbes, 2003; Kluback, 2003; McDermott, 1987).

In light of this assessment, Aurobindo boldly proclaimed:

The coming of a spiritual age must be preceded by the appearance of an increasing number of individuals who are no longer satisfied with the normal intellect, vital, and physical existence of man, but perceive that a greater evolution is the real goal of humanity and attempt to effect it in themselves, and to lead others to it, and make it recognized goal of the race. In proportion as they succeed and the degree they carry this evolution, the yet unrealized potentiality, which they represent, will become an actual possibility of the future. (McDermott 1987; p. 7)

For the first time in the history of the Earth, humankind can consciously participate in its own evolution and in doing so direct its own journey into the future. This phenomenon presents an unprecedented opportunity for educators. Positive dispositions toward globalization can be advanced through meditative actions and reflective thoughts 
opening up inestimable untapped human energies. Political, social and economic problems in which we perceive ourselves as being powerless to solve can be understood as providing us with unique opportunities to advance human progress (Aurobindo, 1985a, 1998a; Bruteau, 1971, 1974; Dalal, 2001, Gandhi, 1992; King, 1989; Kluback, 2003; Monor, 1998).

Again, Aurobindo writes (1974b):

At present mankind is undergoing an evolutionary crisis in which is concealed a choice of its destiny; for a stage has been reached in which the humankind mind has achieved its certain directions and enormous development while in others it stands arrested and bewildered and can no longer find its way. A structure of the material life has been raised up by man's ever active mind and life-will, structure of unmanageable hugeness and complexity...Man has created a system of civilization which has become too big for his limited capacity and understanding. (Aurobindo, 1974b, p. 55)

Some Aurobindo followers argue that what is being defined as globalization is tangible empirical evidence of his theory of human evolution coming to past. Social and political interaction between the West and East, environmental awareness, advancements in science and technology and developments in global education are objective proofs of evolutionary movement toward global-unity and a shift in our collective consciousness (Chaturvedi, 2002; Hamilton, 2004).

K. D. Sethna observes:

He [Aurobindo] kindles a vision and initiates a work that bears on the whole human situation... man in every mode and field-the thinker [educator], the scientist, no less than the artist and mystic-man individual and man collective- the modern breaker of ground side by side with the heir of the ages...Man is a transitional being, he is not final. The step from man to superman is the most approaching achievement of earth's evolution. It is inevitable because it is at once the intention of the inner spirit and the logic of Nature's process. Humankind must shake off the shackles of slavery to ignorance. (Sethna, 1973, p. 7)

Aurobindo challenges educators to participate in social evolution by nurturing the human energy necessary for future progress. He believed that educational institutions are "laboratories of evolution" and teachers are "evolution agents," leaders of the process. Educational curricular activities must be a synthesis of Western positivism with Eastern metaphysics, as well as other global cultural values (Aurobindo, 1995, 2000).

Sri Aurobindo died in the French colony of Pondicherry, India in 1950. Today he is venerated in India as a hero of the people, a champion of social justice, a great Hindu sage and global citizen (Paine, 1998). Mirra Alfassa (aka. the Mother), Aurobindo's wife and life-long colleague, 
who established the Aurobindo Ashram and Educational Laboratory at Pondicherry, reflects on his thought: "Sri Aurobindo has come to announce to the world the beauty of the future that will be realized. He has come to bring not a hope but the certainty of the splendor towards which the world is moving. The world is not an unfortunate accident: it is a miracle moving towards its expression" (Vrekhem, 1997, p.xi).

Some critics may view Aurobindo's thought as being too esoterically speculative to have pragmatic application for a global education agenda. The predictable concern of such critics will be that such futuristic musing distracts us from appropriately educating for present day solutions of real problems that globalization presents educators. Yet while most educators analyze globalization with trepidation, some still wrap their minds tightly around the positive idea of globalization as being an evolutionary epoch moving humankind toward global collaboration and a heightened level of collective planetary consciousness. The belief being that for positive social change to occur, humankind must first be educated for the possibility of such change. Aurobindoian thought is a motif to think anew about globalization that nurtures a sense of Ultimacy for humankind.

Aurobindo States:

The unification of mankind is underway, though only in an imperfect initiative, organized but struggling against tremendous difficulties.... which is not limited by present facts and immediate possibilities but looks into the future and brings it nearer, her presence may make all the difference.... international spirit and outlook must grow up and international forms and institutions; even it may be such developments as dual or multilateral citizenship and a voluntary fusion of cultures may appear in the process of the change....A new spirit of oneness will take hold of the human race...if this evolution is to take place. (Chaturvedi, 2002, pp. 69-71)

In closing, Aurobindo articulates an inspiring vision of Ultimacy regarding the future evolution of humankind and the emergence of a global psycho-social reality that can augment a holistic global education agenda in a new and novel way.

\section{References}

Aurobindo, S. (Ed. R.A. McDermott).(1971). The mind of light. New York: Dutton. Aurobindo, S. (1974a). The life divine. Pondicherry, India: Sri Aurobindo Ashram Press.

Aurobindo, S. (1974b). The future evolution of man: The divine life upon earth. Wheaton, IL: Quest Books-The Theosophical Publishing House.

Aurobindo, S. (1985a). Social evolution towards the ideal of human unity. Pondicherry, India: Sri Aurobindo Ashram Press. 
Aurobindo, S. (1985b). Future poetry. Twin Lakes, WI: Lotus Press. Aurobindo, S. (1990). A synthesis of yoga. Twin Lakes, WI: Lotus Press.

Aurobindo, S. (1991). (6th edition). The superman. Pondicherry, India: Sri Aurobindo Ashram Press.

Aurobindo, S. (1993). Integral yoga: Sri Aurobindo's teaching and method of practice. Twin Lakes, WI: Lotus Press.

Aurobindo, S. (1995) ( $2^{\text {nd }}$ edition). A new education for a new consciousness. Pondicherry, India: Sri Aurobindo Ashram Press.

Aurobindo, S. (1998a). The ideal of human unity. Pondicherry, India: Sri Aurobindo Ashram Press.

Aurobindo, S. (1998b). (2 $2^{\text {nd }}$ edition). Glossary of terms in Sri Aurobindo writings. Pondicherry, India: Sri Aurobindo Ashram Press.

Aurobindo, S. (1998c). The human cycle: The psychology of social development. Twin Lakes, WI: Lotus Press.

Aurobindo, S. (2000). Sri Aurobindo and the mother on education. Twin Lakes, WI: Lotus Press.

Baylis, J., \& Smith. S (Eds). (2001). The globalization of world politics: An introduction to international relations. Oxford, UK: Oxford University Press.

Beck, R. (1999). What is globalization? Cambridge, UK: Polity Press.

Berger, P. L. \& Huntington, S.P.(Eds). (2002). Many globalizations: Cultural diversity in the contemporary world. Oxford, UK: Oxford University Press.

Bhagwati, J. (2004). In defense of globalization. Oxford, UK: Oxford University Press.

Bigelow, B., \& Peterson, B. (Eds). (2002). Rethinking globalization: Teaching for justice in an unjust world. Milwaukee, WI: Rethinking School.

Bloom, H. (2000). Global brain: The evolution of mass mind from the big bang to the $21^{\text {st }}$ century. New York: John Wiley \& Sons.

Bruteau, B. (1971). Worthy is the world: The Hindu philosophy of Sri Aurobindo. Cranbury, NJ: Associated University Press.

Bruteau, B. (1974). Evolution toward divinity: Teilhard de Chardin and the Hindu tradition. Wheaton, ILL: Theosophical Publishing House.

Bruteau, B. (2001). The grand option: Personal transformation and a new creation. Notre Dame, IN: University of Notre Dame Press.

Burbules, N., \& Torres, C.A. (Eds).(2000). Globalization and education: Critical perspectives. New York: Routledge.

Chaturvedi, A.N. (2002). Sri Aurobindo: The spiritual revolutionary. New Delhi, India: Rupa \& Co.

Combs, A. (1996). The radiance of being: Complexity, chaos, and the evolution of consciousness. St. Paul, MN: Paragon Books.

Dalal, A.S. (2001). A greater psychology: An introduction to the thought of Sri Aurobindo. New York: Jeremy P. Tarcher.

Dalal, A.S. (2003). Our many selves: Practical yogic psychology. Twin Lakes, WI: Lotus Press.

Daun, H. (Ed). (2002). Educational restructuring in the context of globalization and national policy. New York: Routledge.

Dowsett, N. C. (1977). Psychology for future education. Pondicherry, India: Sri Aurobindo Society. 
Dowsett, N. C. \& Jayawal, S.R. (1976). Education for the future. Pondicherry, India: Sri Aurobindo Society.

Feys, J. (1977). The yogi and the mystic: Sri Aurobindo and Aurobindo de Chardin. Calcutta, India: Firma KLM Ltd.

Foer, F. (2004). How soccer explains the world: An unlikely theory of globalization. New York: Harper Collins.

Forbes, S. H. (2003). Holistic education: An analysis of its ideas and nature. Brandon, VT: Foundation for Educational Renewal.

Freidman, T. L. (2000). The lexus and the olive tree: Understanding globalization. New York: Anchor Books.

Freidman, T. L. (2005). The world is flat: A brief history of the $21^{\text {st }}$ century. Waterville, ME: Thorndike Press.

Gandhi, K. (1992). ( $2^{\text {nd }}$ edition). Social philosophy of Sri Aurobindo and the new age. Pondicherry, India: Sri Aurobindo Ashram Publication Department.

Hamilton, C. (2004). The future of God, evolution and enlightenment for the $21^{\text {st }}$ Century. The Journal of Yoga. Volume 3, Number 1, January.

Heehs, P. (1989). Sri Aurobindo: A brief biography. Oxford, UK: Oxford University Press.

Heehs, P. (Ed). (1999). The essential writings of Sri Aurobindo. Oxford, UK: Oxford University Press.

Held, D. \& McGrew, A. (2002). Globalization and anti-globalization. Washington, DC: Polity Press.

Held, D., McGrew, A., Goldblatt, D., \& Perraton, J. (1999). Global transformations: Politics, economics and culture. Cambridge, UK: Polity Press.

King, U. (1989). The spirit of one earth: Reflections on Aurobindo de Chardin and global spirituality. New York: Paragon House.

Kluback, W. (2003). Sri Aurobindo Ghose: The dweller in the lands of silence. St. Paul, MN: Paragon House.

Levin, J.S. (2001). Globalizing the community college: Strategies for change in the $21^{\text {st }}$ century. New York: Palgrave Books.

McDermott, R. (Ed). (1987). The essential Aurobindo. New York: Lindsfarne Books.

McGreal, I.P.(1995). Great thinkers of the eastern world. New York: Harper Collins.

Monor, R. (1998). Sri Aurobindo: The perfect and the good. Firma KLM:

Mukherjee, J.K (1990). From man human to man divine: Sri Aurobindo's vision of the evolutionary destiny of man. Pondicherry, India: Sri Aurobindo International Center for Education.

Overzee, A. H. (1992). The body divine: The symbol of the body in the works of Aurobindo, Teilhard de Chardin and Ramanuja. Cambridge, UK: Cambridge University Press.

Paine, J. (1998). Father India: How encounters with an ancient culture transformed the modern west. New York: Harper Collins.

Peterson, R., Wunder, D.F. \& Mueller, H.L. (1999). Social problems: Globalization in the twenty-first century. Upper Saddle River, NJ: Prentice Hall.

Purani, A.B. (2001). ( th $^{\text {th }}$ edition). The life of Sri Aurobindo. Pondicherry, India: Sri Aurobindo Ashram Press.

Rishabachand. (1993). The integral yoga of Sri Aurobindo. Twin Lakes, WI: 


\section{Aurobindo's Thought and Holistic Global Education}

Lotus Press.

Rizvi, F. \& Lingard, B. (Eds). (2000). Symposium on globalization and education. Educational Theory, 50(4).

Satprem. (Trans.Luc Venet).(1984). SriAurobindo or the adventure of conscious ness. New York: The Institute for Evolutionary Research.

Satprem. (Trans. Luc Venet). (1985). On the way to supermanhood. New York: The Institute for Evolutionary Research.

Sethna, K.D. (1973). Teilhard de Chardin and Sri Aurobindo. A focus on fundamentals. India: Bharatiya Vidya Prakasan.

Sethna, K.D. (1981). The spirituality of the future: A search apropos of R.C. Zaehner's study on Sri Aurobindo and Teilhard de Chardin. London, UK: Associated University Press.

Singh, K. (1989). The prophet of Indian nationalism. India: Bharatiya Vidya Bhavan.

Steger, M. B. (2001). Globalization: The new market ideology. New York: Rowan \& Littlefield.

Stiglitz, J. E. (2002). Globalization and its discontents. New York: W.W. Norton.

Stromquist, N. P. (2002). Education in a globalized world: The connectivity of economic power, technology, and knowledge. Lanham, MD: Rowan \& Littlefield.

Stromquist, N.P., \& Monkman, K. (Eds).(2000). Globalization andeducation:Integration and contestation across cultures. Lanham, MD: Rowman \& Littlefield.

Susai, A. (1993). The neo-Hindu concept of man: In the light of Sri Aurobindo's evolutionary vision. New Delhi, India: Intercultural Publications.

Varma, V.P. (1998). The political philosophy of Sri Aurobindo. India: Motilal Banarsidas.

Vrekehm, G.V. (1998). Beyond the human species: The Life and work of Sri Aurobindo and the Mother. St. Paul, MN: Paragon House.

Wygant Jr., W.E. (2001). Of one blood: A study of the parallels in Christianity and Sri Aurobindo's integral philosophy. Haverford, PA: Buy Books.

Zaehner, R.C. (1971). Evolution in religion: A study of Teilhard de Chardin and Sri Aurobindo. Oxford, OK: Clarendon Press.

\section{Appendix}

DIAGRAM 1: Aurobindoian Idea of Global Psyche-Social Evolution

HUMAN SOLIDARITY and GLOBAL UNITY
(The Ultimacy of Globalization)

(Evolution of Collective Global Consciouosness)

Over-Mind (transitional evolutionary state)

Metaphysical Realm (Higher consciousness/spiritual) Intuitive Mind

Intellectual Realm (Psyche-social ) Illuminated Mind

Higher Mind (transitional evolutionary state)

Life Realm (Biological)

Vital Mind

Material Realm (Physical)

Physical Mind

EVOLUTION OF CONSCIOUSNESS 